This is the author's Post-print version (final draft post-refereeing as accepted for publication by the journal). The definitive, peer-reviewed and edited version of this article is published as: van Ham M., Mulder C.H. and Hooimeijer P. (2001) Spatial flexibility in job mobility: macro-level opportunities and micro-level restrictions. Environment and Planning A 33, 921-940. http://dx.doi.org/10.1068/a33164

\title{
Spatial flexibility in job mobility: macro-level opportunities and micro-level restrictions
}

\author{
Maarten van Ham, Clara H. Mulder and Pieter Hooimeijer \\ Urban Research centre Utrecht (URU), Faculty of Geographical Sciences, Utrecht University, \\ P.O. Box 80.115, 3508 TC Utrecht, The Netherlands (fax: 31-30-2532037, e-mail: \\ m.vanham@geog.uu.nl)
}

\begin{abstract}
Disequilibria among regional labour markets persist through spatial inflexibility in job mobility resulting from restrictions in migration and long-distance commuting. This contribution analyses workplace mobility-the acceptance of a job at a great distance from the place of residence-using a direct measure which includes both migration and long commutes as means for covering this distance. Two sources of spatial inflexibility are identified. The first is a low overall chance of general job mobility; the second is a limited search area leading to low workplace mobility. In a two-step analysis we show that workers who find another job are a highly selective group. Within this group the variation in accepting a job at a great distance is wide, because of the individual restrictions that are often gendered. We also show that ample availability of job opportunities stimulates general job mobility and reduces workplace mobility, but only after controlling for individual restrictions. These findings are in line with the spatial mismatch hypothesis.
\end{abstract}

\section{Introduction}

Job mobility allows individuals to take advantage of alternative job opportunities, thus serving as a mechanism for upward social mobility (Lichter, 1983), or as a means of avoiding un(der)employment (Simpson, 1992). Faced with a lack of suitable job opportunities on the local labour market, a job searcher has three options (see also Simpson, 1992). The first is to stay put in the present job, or in the current state of unemployment. The second option is to accept a local job for which one is overqualified. The third option is to search a larger area and accept a job at a greater distance: workplace mobility. The first and second options lead to underemployment. The third option requires people to be more spatially flexible: they will have to migrate, or stretch their commuting tolerance — the maximum time they are willing to travel for a day at work. Assuming that everyone would prefer to maximize the return on human capital, the choice of option is a matter of restrictions rather than preference.

In this paper we define job mobility as accepting a job by the unemployed or by those already in employment. From a human capital point of view both the employed and the unemployed will accept a job to increase the return on their human capital. Spatial flexibility is the possibility of accepting a job at a greater distance. Workplace mobility is a special case of general job mobility: accepting a job at a greater distance. 
Workplace mobility plays an important part in clearing the national labour market by reducing a coexisting surplus of demand and supply in regional markets. But at the individual level, workplace mobility also leads to higher mobility costs in the form of commuting or migration. Individual restrictions in meeting these costs might severely hamper the clearing of the labour market at the national level. This disequilibrium problem is well known in the migration literature. Ballard and Clark (1981) for instance show that regions with a lack of suitable job opportunities sometimes have lower rather than higher outmigration rates. They resolved this paradox by taking the selectivity of migration into account. As the more mobile leave the area, the migration propensity decreases, because the less mobile remain behind. A lack of suitable job opportunities at the place of residence is the trigger for the migration decision of those who have left.

The three options identified above show that the disequilibrium problem has only been partly defined in the migration literature. The start of the disequilibrium is geographical disparity in job access-the number of suitable local job opportunities-without which accepting a job at a greater distance could be avoided altogether. Migration is only one of the means of accepting a job at a greater distance; the other is stretching the commuting tolerance. Together, migration and commuting tolerance determine an individual's spatial flexibility. Measured in terms of distance, commuting tolerance has undoubtedly grown over the past few decades, through faster means of transport. In contrast, migration tolerance is affected negatively by the rising share of dual-earner households. Dual-earner households have a lower propensity to make a residential move than couples or families with a single breadwinner (Mulder, 1993; Mulder and Hooimeijer, 1999; Jarvis, 1999), but may accept a longer commute.

Since migration and commuting are substitutes in spatial flexibility, analysing only one of them yields a partial understanding of workplace mobility. More importantly, the options show that there are two sources of the selectivity in accepting a job at a larger distance. The first is an overall low chance of finding another job which makes people stay put in their jobs or in unemployment. The second is that people who are able to find another job, but are restricted in their search area, choose the second option rather than the third. The mechanisms affecting these choices are different. In general, a low level of job mobility leads to staying put. Spatial inflexibility leads to accepting a job closer to home. The determinants of these two types of inflexibility are not necessarily the same.

Although an extensive body of research has identified the main determinants of job mobility, little is known as yet about the determinants of workplace mobility. Moreover, the existing literature on job mobility pays little attention to job access. Only the monetary costs of commuting and migration are taken into consideration, not the availability of jobs. Relatively little labour economics research has been formulated in a truly spatial context (Crampton, 1997). Spatial labour market behaviour is, however, determined by more than just the cost of covering distance. Job access also plays a role (Hanson and Pratt, 1991; Fisher and Nijkamp, 1987).

A more comprehensive approach to the role of space in job mobility is needed: an approach in which general job mobility and workplace mobility can be separated, in which workplace mobility is measured directly and not via migration or commuting, and in which access to job opportunities enters the analyses after factors determining spatial flexibility at the individual level have been taken into account. The aim of this article is to provide such an approach.

We present a two-step analysis. In the first step we analyse the odds that people find a(nother) job in a given time period: job mobility. In the second step we analyse the odds that people who accept a job do so outside a range of 45 kilometres from their place of residence: 
workplace mobility. The 45 kilometre range corresponds to an average commuting time of 30 minutes by car. The results from the first step are used to correct for the selectivity in general job mobility in the second step. In both the first and second step, we include job access as an independent variable. The main hypothesis is that people living in a location with poor job access show lower odds of general mobility and higher odds of accepting a job over a long distance after controlling for the determinants of spatial inflexibility.

The data on individual characteristics and behaviour come from the Netherlands Labour Force Surveys (EBB) 1994-1997. We have used retrospective information on job mobility in the year preceding the interviews, including the distance to the new job from the original place of residence. The data on job opportunities were derived from the National Information System of Employment (LISA). Job access of residential locations is measured as the absolute number of jobs, by job level, which can be reached within 30 minutes by car from that location. Job access is estimated with the use of a network-oriented Geographic Information System extension (see Van Ham, Hooimeijer and Mulder, 2001). The variable is matched to the behavioural data using the postcode of the residential locations as a key.

\section{Job mobility, workplace mobility and job access}

Our theoretical framework elaborates the three options identified in the introduction: staying put; accepting a job nearby even if it is below one's educational level; widening the search area. The starting point for our conceptualization is that workplace mobility is a special case of job mobility in general; among those who accept a job, only a selective group of workers accept a job at a greater distance. The review of the literature commences with a discussion of the determinants of general job mobility. Next, we focus on the determinants of workplace mobility. We discuss spatial flexibility and restrictions; which individual characteristics determine individual opportunities for workplace mobility? After that, we place job and workplace mobility in a spatial context by including job access in our theoretical framework. The theoretical basis of the framework is essentially economic, drawing on aspects of human capital and search theory.

\subsection{Human capital and job mobility}

The most prominent and widely documented fact about job mobility is that on average, workers change job less with increasing age and experience. Topel and Ward (1992) reported that young men made more than two-thirds of their lifetime job changes during their first 10 years of work experience (see also Booth et al, 1999). The age effect on job mobility can be explained by human capital theory (Becker, 1962). Over the years, workers invest in productivity enhancing skills and strive to maximize the utility of this accumulated human capital. The stock of human capital people acquire during a lifetime has three main components. The first is the general human capital, commonly acquired through the educational system, which enhances productivity equally in all sectors. The second is the sector-specific human capital (Simpson, 1992). This human capital only enhances productivity in a specific sector of the economy. The third component is the enterprise-specific human capital which is acquired with tenure (on-the-job training) and is not transferable across employers. The sector and firm capital can be lost when people accept another job. If older workers have longer tenures and therefore more specific human capital than younger workers, the wage gains of job-to-job mobility would thus be lower for older workers. In addition, older workers have fewer remaining years of work in which to recoup the costs of a job change (Mincer, 1962). 
Viewpoints differ with regard to the effect of education on job mobility. According to Bartel and Lichtenberg (1987), more highly educated workers tend to have faster moving careers and change jobs more often as an institutional requirement for climbing the career ladder. Bartel and Lichtenberg argue that there ought to be considerable job mobility among highly educated workers. However, Börsch-Supan (1990) found that people with a high level of education are less likely to change jobs. This finding is consistent with the theory of firmspecific capital. Workers seem to accumulate more skill and knowledge specific to a firm if they have a higher level of education. This firm-specific capital increases job duration and inhibits job mobility.

Unemployed people do not utilize their accumulated human capital and therefore face considerable loss of income. Further, unemployment, and especially long term unemployment, leads to loss of skills. Based on the human capital theory and after controlling for educational level, we would expect being unemployed to have a positive influence on the probability of accepting a job.

The labour force participation of women is lower than that of men. Women, whether participating or not, are also less often engaged in job search than men (Keith and McWilliams, 1999; Van Ham, Mulder and Hooimeijer, forthcoming). According to the "new home economics', this difference is a result of women's lower wage rates (Becker 1975, 1991), generating a division of labour in which women undertake most of the household and childcare responsibilities. Apart from micro-economic factors, traditional attitudes with respect to women and child-raising also play a part (Hanson and Pratt 1990; 1995, Pratt and Hanson 1991). As a result, many women with spouses, particularly those with working spouses, place a low priority on pursuing a career (Van Ommeren, Rietveld and Nijkamp, 1999). We expected women, particularly those in two-earner households, to show less job mobility than men. We further expected that, for women, the presence of young children in the household would negatively influence job mobility.

According to Gilbert (1998) much research disregards the effect of gender on labour market outcomes. She argues however that especially for women ethnicity and racism play an important role. A lack of language skills and discrimination by employers can cause ethnic minority groups to be less mobile. Further, as Gilbert argues, especially women from ethnic minorities are more spatially constrained which may lead to reduced job mobility. Based on the above we expected the downward effect of being an immigrant on job mobility to be stronger for females than for males.

\subsection{Determinants of workplace mobility}

Many people are more or less fixed in space as a result of limited possibilities for long distance commuting and job related migration. Those who accept a job at a greater distance are a very selective group. We have denoted the possibility of accepting a job at a greater distance as 'spatial flexibility'. Large variations in spatial flexibility - and therefore the probability of accepting a job at a greater distance-were expected for various socio-economic groups. To some extent the determinants of workplace mobility overlap those of general job mobility.

The role of age is based on a mechanism which resembles the effect of the accumulation of sector or firm specific human capital. Older people also accumulate more location specific capital which inhibits spatial mobility (DaVanzo, 1981). Older workers tend to have greater direct costs, because of home ownership and family obligations, and higher psychic costs of leaving familiar surroundings (Sjaastad, 1962; Polachek and Hovarth, 1977), We therefore expected that as people got older the probability of accepting a job at a greater distance would decrease rapidly. 
According to Börsch-Supan (1990), when people with a high level of education accept a job, they more often do so at a greater distance. This effect of education is consistent with the theory of search and transaction costs. These costs decrease with level of education, because highly educated individuals are likely to accumulate more information and process information more efficiently. Education is said to be associated with greater knowledge of alternative opportunities (March and Simon, 1958). Furthermore, jobs requiring a high level of education are more spatially dispersed than jobs at a lower level. We therefore expected the highly educated to be more spatially mobile: they have to search larger areas to find a suitable job (Simpson, 1992). According to DaVanzo (1978), economic theory suggests that, other things being equal, the unemployed are more spatially flexible, because they have lower opportunity costs of moving and less job-specific capital than the employed. They are expected to be more responsive to job opportunities elsewhere and therefore to accept jobs at a greater distance more often.

Findings from the literature on job-related migration and commuting led us to expect gender and household situation to be important determinants of workplace mobility. Women have been shown to have shorter commuting distances and times than men (Blumen, 1994; Gordon et al, 1989; McLafferty and Preston, 1997; Turner and Niemeijer, 1997). According to Madden (1981), gender differences in household roles are important in influencing women to accept jobs closer to home (see also Johnston-Anumonwo, 1992, on the household responsibility hypothesis). Because women face more time-space constraints than men, we expected them to show less workplace mobility. We further expected that the presence of children in a household would cause women to reduce their workplace mobility more than men (see also Baccaïni, 1997; Rouwendal, 1999).

Having a partner would also be expected to influence workplace mobility. Human capital theory (Polachek and Hovarth, 1977; Mincer, 1978) argues that married workers are less likely to move, because of the greater direct moving costs, the need to offset the psychic costs for both spouses, and the likelihood that a move may result in lost employment or income for the tied mover. Lower mobility among married people is indeed found (Ritchey, 1976; Mincer, 1978; DaVanzo, 1981). Job related long distance migration has also been found to be lower among dual-earners than among one-earner couples (Wagner, 1989, for Germany; Mulder, 1993 for The Netherlands; Bartel, 1979, Lichter, 1982 for the US). For a two-earner household, any change of geographic location is likely to be more expensive than for oneearner families (Shaklee, 1989). This lack of migration tolerance among couples might be compensated by a larger commuting tolerance among the male partners in particular. The presence of a partner to deal with domestic chores and childcare would widen the time-budget of the other partner. We would therefore expect cohabiting and married women to be less spatially mobile than singles, while we would not expect such an effect for men.

The characteristics of the accepted job were also expected to influence the distance at which a job is accepted. Accepting a job at a greater distance requires high investments in the form of commuting or migration. Clearly, migration is only worthwhile when the returns are sufficiently high (Sjaastad, 1962). People would probably be less willing to accept a job located at some distance from their residence for a part-time position (compare Giuliano, 1998). The return on investment in workplace mobility is highest for high-level jobs. Several studies show a positive relationship between occupational level (or income) and actual geographical mobility (Duncan and Perrucci, 1976; Ritchey, 1976; Polachek and Hovarth, 1977; Lichter, 1980), or the willingness to move (Fernandez, 1981; Markham et al, 1983). Markham and Pleck (1986) expected a positive effect of occupational level on willingness to move, because of the wider geographical dispersion of labour pools for specialized jobs and the greater visibility to such employees of jobs in other locations. 
The economic sector might also have an influence on workplace mobility, because of the uneven spatial distribution of jobs between sectors. It is easy for example to imagine that jobs in healthcare are more widely dispersed than jobs in the petrochemical industry, so workers in one sector might have to be more spatially mobile than those in another sector.

Undoubtedly, commuting distance to the former job also plays a part. For those who already had a long commute, the new job might be closer rather than further away. Furthermore, some people have adjusted their lives to long commutes and are used, for example, to combining their commuting trip with shopping, or taking their children to childcare facilities. We therefore expected that workers who already commuted over long distance in their previous job are more spatially mobile when accepting a new job.

\subsection{Job access of residential locations as a spatial context variable}

People change job to make career advancement. Career advancement through job mobility is only possible if suitable employment is available and accessible. When access to suitable local job opportunities within reasonable commuting time is poor, workplace mobility is a means of escaping underemployment that results from the spatial mismatch between supply and demand (see also Simpson, 1992).

The 'spatial mismatch hypothesis' as formulated by Kain (1968) was “originally coined to describe a broad set of geographical barriers to employment for African-American inner city residents" (Preston and McLafferty, 1999: 387), but has wider implications. Central in the spatial mismatch debate is that poor geographical access to jobs reduces employment opportunities and negatively influences labour market outcomes. Kain already described the importance of transportation in shaping access to employment (Preston and McLafferty, 1999). The mechanisms that cause underemployment in the case of spatial mismatch are a combination of individual restrictions with a wider overall context of poor job access.

The availability of employment opportunities largely depends on the spatial configuration of suitable employment relative to the location where someone lives (see Van Ham, Hooimeijer and Mulder, 2001). Fielding (1992) has shown for the UK that at the national level migration towards the employment-rich South East England generates positive labour market outcomes (see also Fielding and Halford, 1993). At the regional level it is important to differentiate between social groups. According to Hanson and Pratt in their book 'Gender, Work, and Space' $(1995 ; 119)$ “for people looking for work close to home (most of whom are women), the residential location on this landscape, the location from which the job search begins, importantly defines access to different kinds of work". In discussing job availability, the segmentation of the labour market should be taken into account. Workers differ in their level and degree of specialisation of human capital and jobs differ by level. Only a subset of all the jobs within reach is suitable for an individual job searcher (Hanson and Pratt, 1995). Assuming that all job searchers want to maximize the returns on previous investments in human capital, they will search for jobs where these returns can be maximized (see also Becker, 1962).

Accessibility of jobs is determined by the spatial flexibility of individual workers. Phelps (1970) pictured the economy as a group of 'local labour market islands' between which moves are costly. The cost of covering the distance between islands inhibits workers from accepting jobs located on other islands. Hägerstrand (1970) recognized that, besides monetary costs, time is also an important constraint on spatial flexibility. From a fixed residential location, the journey to and from work is only possible when this occurs within an individual's daily activity space. According to this line of reasoning, a job is accessible as long as it can be reached on a daily basis within an acceptable commuting time. Most people's commuting tolerance is limited: 45 minutes' commuting is the maximum for most employees 
(Wachs and Taylor, 1993; Van Ommeren, 1996). In practice, Wachs and Taylor (1993) find for the US that almost two thirds of all employees spend less than 35 minutes commuting to work. In the Netherlands, $80 \%$ of all employees spend half an hour or less (Van Ham, Hooimeijer and Mulder, 2001). Given these empirical results it seems reasonable to assume that for the Netherlands job access can be defined as the number of suitable jobs which can be reached from the residence within 30 minutes.

The conclusion regarding the effect of job access on (spatial) job mobility is twofold. First, access to suitable employment increases the probability that one can find a better job. We therefore hypothesise that living in a location with good access to suitable employment leads to more job mobility. Because women are less spatially flexible than men are, we further hypothesise that for women job access has a stronger effect on job mobility. Second, we deduce from the spatial mismatch hypothesis that workplace mobility is a means to overcome poor local job access. We therefore expected that people living in locations with poor job access and unable to reach a reasonable number of suitable jobs within reasonable commuting time would have to be more spatially flexible and, as a consequence, be more likely to accept jobs at a greater distance.

Summarising, we have formulated a number of hypotheses both with respect to general job mobility and workplace mobility (see table 1). For both we expect that mobility will decrease with age and will be higher among the unemployed. With respect to education we have formulated competing hypotheses on the effect on job mobility and expect a positive effect on workplace mobility. We have also formulated contrasting hypotheses for men and women with respect to the role of the household situation. Having a partner will decrease the mobility among females. Having a child will reduce mobility among both sexes, but more particular among the females. Ample job access will have a positive effect on general job mobility as it increases the opportunities for career advancement, but will have a negative effect on workplace mobility as it decreases the need to widen the search area.

Further factors leading to higher workplace mobility are: the number of hours worked, the level of the job and a large commuting distance at the start of the observation period. We expect varying effects of the sector in the economy, depending on the geographical dispersal (negative) or concentration (positive) of the jobs.

Table 1. List of hypotheses

\section{Data and methodology}

The implications of these theoretical considerations for the empirical analyses are farreaching. The relationship between poor job access and workplace mobility is not straightforward. Whether people accept a job at a greater distance also depends on the chances of finding another job and on the size of the search area. To a considerable extent, the determinants of the chances of finding another job and of spatial restrictions that limit the search area overlap. For instance, a higher level of education enhances the chances of finding a job, requires people to search a wider area, and increases the returns on the decision to accept a job at a greater distance. Analysing the role of spatial restrictions would therefore lead to biased results if the selectivity of the group finding a job at all were ignored. To analyse the relationship between job access and workplace mobility, one needs to correct for this selectivity and to control for spatial restrictions at the individual level. Many of the determinants are gendered and are therefore, expected to have different effects for men and 
women. Separate analyses are a pragmatic choice to avoid the inclusion of too many interaction effects in the empirical models.

The data used in this paper were derived from the Netherlands Labour Force Surveys (EBB) conducted in 1994, 1995, 1996 and 1997 by Statistics Netherlands. The data set includes detailed information concerning individual and household characteristics, such as level of education, number of children, job characteristics, partner characteristics and detailed information on the workplace and the residential location. Furthermore, the dataset includes information on where the respondent worked and lived one year before the interview.

The analyses were restricted to respondents aged between 15 and 54 years excluding students, the armed services, the self-employed, workers without a fixed working address, and the disabled. After this selection, the data set amounted to 144,050 men and 156,295 women. In total, 15,171 men and 14,377 women accepted a job in the year before the interview. Men and women have been analysed separately. First, we analysed labour market flexibility in general: whether or not people accept a job. Second, for the selective group of workers who accepted a job, we analysed whether or not they accepted a job at a greater distance. In both analyses the dependent variable is dichotomous; we have therefore used logistic regression models.

In the second analysis we have included only those who accepted a job in the year before the interview. To correct for this selectivity, we used Heckman's two-step procedure (Heckman, 1979), by including a correction factor Lambda in the analyses of job acceptance at a greater distance. In its transformed form Lambda represents the inverse of the predicted probabilities of accepting a job from the first model. The first and second analyses need to have different sets of independent variables so as to avoid multi-collinearity between Lambda and the subset of independent variables in the second model. For this reason the variables 'immigrant or descendant' and 'year of interview' are only included in the first model.

\subsection{Variables}

The dependent variable in the analysis of job acceptance measures whether people accepted a job in the year before the interview. Eight independent variables have been included. Level of education is measured in five categories: primary education; lower-level secondary education; upper-level secondary education; higher vocational education; university. Age is measured in seven categories: younger than 25 ; 25-29 years; $30-34$ years; $35-39$ years; $40-44$ years; $45-49$ years; 50-54 years. The type of household is categorized as: single; couple with non-employed partner; couple with working partner; others (predominantly children living with their parents). Dummy variables indicate whether there was a child younger than five years old present in the household, and whether a respondent was of foreign origin (immigrants and their descendants being coded as one category in the data). The year of interview is indicated in four categories: 1994; 1995; 1996; 1997. Labour force status a year before the interview is measured as employed, or not employed. Job access is included as a continuous variable (see 3.2 for method).

The dependent variable in the analysis of workplace mobility measures whether people accepted a job at a greater distance. We defined long distance as 45 kilometres or more. We would have preferred to use a direct measure of travelling time, but unfortunately it was not possible to calculate an accurate estimate of the travelling time between the two locations. Instead, we decided on this 45-kilometre threshold because this is the distance that, on average, can be covered in about 30 minutes of travel time. In the theoretical part of this paper (see 2.3) we saw that this is a reasonable approximation of the maximum time people are willing to commute. For all respondents who accepted a job in the year before the interview 
we calculated the distance in kilometres between the place of residence one year before the interview and their present job: this is the distance at which they accepted a job.

In the analysis of workplace mobility, ten independent variables and the correction factor Lambda have been included. Age, level of education, type of household and job access are measured in the same way as in the first analysis. The presence of children is categorized in more detail as: no children; youngest child under six years old; youngest child between six and 12 years old; youngest child between 12 and 17 years old. Hours worked per week are in four categories: 12-20 hours; 21-35 hours; 36-40 hours; more than 40 hours a week.

The variable job level was developed by Statistics Netherlands. Job levels are assigned to jobs on the basis of the Standard Job Classification (SBC-1992, see CBS, 1993). Job levels are defined by the amount of theoretical or practical schooling needed to perform the task adequately and needed working experience (or training time). Five job levels are distinguished: elementary; low; middle; high; graduate. Job sector is categorized as: manufacturing and agriculture; construction; transport and communication; wholesale and retail trade; hotels and restaurants; financial and business services; public administration; education and health; community, social and personal services. Together, job level and sector, are the best proxies available of the occupational differentiation in skills from more ubiquitous towards highly specialised jobs and in geographical distribution from widely dispersed towards highly concentrated jobs. The data do not allow us to differentiate between jobs in the 'old' or the 'new' economy.

Labour force status one year before the interview is defined as employed or not employed. A respondent's commute for the previous job at a greater distance is defined in an analogous manner to the dependent variable. A commuting trip of more than 45 kilometres one year before the interview is considered a long distance. For respondents without a job one year before the interview the 'former commuting trip' variable is missing. In order to be able to include these respondents in the analyses we used the substitution of the means method. For the respondents without a job one year before the interview, the average of the respondents with a job has been substituted for this dummy. This substitution of the means leads to unbiased coefficients of the dummy for those with a job one year before the interview (compare Cohen and Cohen, 1975, Chapter 7).

\subsection{Measuring the job access of residential locations}

The job access of a residential location is measured as the absolute number of jobs, by job level, which can be reached within 30 minutes by car from that location. Two important choices underlie the way we measured job access. The first is that we decided to use a 30minute threshold instead of a smooth travelling time trade off. The reasoning behind this is that in the Netherlands nearly $90 \%$ of commuters use private modes of transport and $80 \%$ of the working population travels less than 30 minutes per single journey to work. Our threshold of 30 minutes travelling by car is therefore thought to be a reasonable measure of local labour market access (Van Ham, Hooimeijer and Mulder, 2001). Second, we decided to use absolute measures of the number of jobs within reach instead of applying some correction for the competition for these jobs from other job searchers residing in the same area. We do so, because what we are interested in, is a measure of the size of the total opportunity set, as this size determines the probability of a suitable job becoming available.

Job access of residential locations should be measured at a detailed geographical level to account for the spatial distribution of jobs in dispersed locations. The finest measurement of residential locations in our dataset are the almost 4000 four-digit postcode areas. The role of the transportation network in measuring job access is crucial, since the transportation infrastructure links residences to jobs. We therefore have to take into account the quality of 
the connection in terms of the average travelling speed on each road segment. To handle the geographical detail and the measurement of travelling times over the road network, the choice for a Geographical Information System (GIS) has become popular in spatial mismatch research (Hanson et al, 1997; Ong and Blumenberg, 1998). We used FLOWMAP, a networkoriented GIS-extension developed at the Faculty of Geographical Sciences, Utrecht University (De Jong and Floor, 1993) to calculate the number of jobs within thirty minutes by car, using a fastest path algorithm.

For data on the spatial distribution of jobs we used the 1991 and 1994 National Information System of Employment ${ }^{1}$ (LISA). This is a registration of nearly all the establishments in the Netherlands, including government and other non-commercial organizations. An establishment is defined as an individual plant, store, or office; multiestablishment firms have separate listings for each establishment. The dataset includes information on total employment per establishment and the location of each job site by address. To estimate job access on the basis of the LISA data set, all establishments were geocoded to a postal code area using work site addresses. Unfortunately, LISA does not contain information on job levels. By combining the LISA data and the data from the Netherlands Labour Force Surveys (EBB) we estimated the number of jobs by level (using the 5 SBC-1992 job levels) for each 4-digit postcode area. FlowMAP was used to generate proximity counts, the number of jobs per level that can be reached within 30 minutes by car, for each postcode (see Van Ham, Hooimeijer and Mulder 2001 for a more detailed description of the method used). We allotted a measure of job access to all the respondents on the basis of their residential location and their educational level.

Figure 1 shows the enormous differentiation in the total number of jobs that can be reached within 30 minutes from residential locations. As can be expected, job access is high from locations in and around the four major concentrations of employment opportunities: the cities of Amsterdam, Rotterdam, The Hague, and Utrecht. In line with the original spatial mismatch hypothesis, the locations in between these cities, not the four largest cities themselves, show the highest job access. The four cities are located relatively close to each other, so people living in between them can reach more than one concentration of employment within 30 minutes (see also Van Ham, Hooimeijer and Mulder, 2001). The worst job access, however, is found in peripheral locations. This finding corresponds with the idea of the central urban area as an 'escalator region', offering ample opportunities for the upwardly mobile (Fielding, 1992).

Figure 1. Job access within 30 minutes (number of jobs).

Source: LISA 1991 and 1994, based on own calculations.

\section{Results}

\subsection{Job mobility}

Just over 10 percent of the men and 9 percent of the women found another job in the year preceding the interview. Table 2 gives the results of the analysis of job mobility. The analyses were run separately for men and women as we hypothesised marked differences between these two.

As expected, the probability of finding a job decreases with age. The probability of job mobility increases with level of education. This finding is in contrast with that of BörschSupan (1990) in the US and supports the hypothesis of Bartel and Lichtenberg (1987) that 
more highly educated workers change jobs more often. As expected, employed people find another job less often than unemployed people. Previous work on job search behaviour ( Van Ham, Mulder and Hooimeijer, forthcoming) shows that this higher level of mobility among the unemployed can be related to the search intensities. Most factors (like age, education, etc.) that drive the search, are identical for the employed and the unemployed, but the overall search intensity among the latter group is understandably higher. We therefore included only the main effect for employment status in this analysis and concentrate on gender differentials in the following.

Table 2. Logistic regression of job mobility by gender

Although the signs of the age and education parameters are identical for men and women, the magnitudes are clearly different. The constant is significantly more negative in the model for women, indicating overall lower job mobility. The age effect is more strongly negative for women than for men. The odds for a woman aged between 50 and 54 finding a job are 0.05 times the odds for a women aged under 25 finding a job. The educational effect is strongly positive. The odds for a woman with a university degree finding a job are six times higher than for women with only primary education; for men, these odds are only three times as high.

Among the more highly educated (with at least higher vocational training) the stronger educational effect for women compensates for the lower constant and the more marked ageeffect up to the age of 45 . In other words, within the group of younger singles with a higher education, the odds for job mobility for men and women are roughly the same. Gender differences show up in particular among older people and people with less human capital.

Marked gender differences are brought about by the position in the household. Men with a partner are more mobile than single men while women with a partner are less mobile than single women. Having a partner apparently allows men to be more active or successful in the labour market, while for women having a partner hampers their job mobility. The presence of a child under five years old in the household exacerbates this effect. Having young children has only a small negative effect on job mobility for men and a strong negative effect for women. For women with a child under five in the household, the odds for accepting a job are 0.37 times the odds for women without a child under five.

As expected, immigrants and their descendants are less mobile than non-immigrants. The lower chances in the labour market of migrants might be due to less skill (language), or discrimination by employers. Opposite to what was expected, male immigrants are less mobile than female immigrants. Year of the interview has been included in the model to avoid multicolinearity and unstable parameter estimates when we include Lambda in the model of workplace mobility to control for selection effects. The results show that the year of interview has a significant effect on job mobility. People interviewed in more recent years are more mobile. This effect probably results from the rapid growth in the demand for labour in the Netherlands at the end of the 1990s.

The effect of job access confirms the hypothesis we deduced from the spatial mismatch debate: living on a location with good access to suitable employment leads to more job mobility. As expected, for women the effect of job access on job mobility is stronger than for men. Because women are less spatially flexible, they are more dependent on local jobs.

\subsection{Workplace mobility: accepting a job at a greater distance}

Table 3 presents the results of the analysis of workplace mobility. Of those respondents who accepted a job, 14 percent of the men and 8 percent of the women accepted a job at a greater 
distance. The research population consists of respondents who found a job in the year before the interview. The dependent variable measures whether or not the respondent accepted a job over a greater distance. Only the models corrected for selection effects are presented.

\section{Table 3. Logistic regression of workplace mobility by gender}

As expected, as age rises people are less likely to accept a job at a greater distance. For men, the effect of age is not significant in a model without correction for selection effects (not shown). This result indicates that our population is selective by age. Because job mobility in general decreases with age, our population, which only includes people who accepted a job, consists of a selective group of older workers who are still active on the labour market. These workers are not a representative sample of the whole population of older workers and therefore our parameter estimates in the model without correction are biased. When we correct for the fact that the population is selective by age, the unbiased parameters show that, as expected, workplace mobility indeed decreases with age.

Also as expected, level of education has a positive effect on the probability of accepting a job over a greater distance, for both men and women. This confirms the findings of Börsch-Supan (1990) that when more highly educated people accept a job they tend to do so at a greater distance than the less well educated. The age effect is stronger for women than for men, although the difference is less marked than in the model of general job mobility. The odds for a woman aged between 50 and 54 accepting a job at a greater distance are 0.16 times the odds for a women aged under 25 accepting a job at a greater distance (and not 0.05 , as in general job mobility). The odds for a university graduate accepting a job at a greater distance are almost 4 and more than 6 times as high, for men and women respectively, as for a person with only primary education.

These results lead to the interesting observation that single women with higher education are more spatially mobile than comparable men. The constant shows that there is no overall lower workplace mobility for women. Gender differences arise in particular from the position in the household, as the parameters of these variables show. For men, having a partner has no effect on the probability of accepting a job at a greater distance. Women with a working partner are less spatially mobile than single women. The effect of having children on workplace mobility is also as expected; for men there is no effect, but for women there is a negative effect. Both findings confirm that women partners, particularly mothers, and not women in general are more spatially constrained than men.

The findings for men are contrary to the results from the migration literature; married or cohabiting men and fathers are not less spatially flexible than single men and men without children. Clearly, the inclusion of both migrations and long commutes in our dependent variables accounts for this difference. The household situation ties men to their place of residence, but does not preclude long commutes as a means of spatial flexibility. Workers in the category 'other' are less spatially mobile than other workers. This can be explained by the fact that these workers are predominantly children still living with their parents.

The effect of the number of hours worked per week points in the same direction. Working part-time does not decrease men's workplace mobility. For women we see a significant but small effect: the more hours they work, the higher the probability of their accepting a job at a greater distance. This finding indicates that women combining paid labour with domestic duties are more sensitive to distance than men in part-time jobs. As expected, the level of the job has a positive effect on workplace mobility.

Sector also has a significant effect on workplace mobility. Men working in the construction sector, financial and business services and public administration are the most 
spatially mobile. Men working in education and healthcare are the least spatially mobile. These effects are thought to relate to differences in the spatial distribution of jobs in different sectors. People do not need to be spatially mobile to get a job in education or healthcare, because these jobs are more evenly distributed over the country than, for example, jobs in finance. Again, gender differences show up. The effects of job level and particularly of sector are less strong for men than for women. This finding would indicate that women can transfer their human capital more readily between firms and between sectors, probably because they are in less specialized jobs.

For men, being unemployed has a positive effect on workplace mobility. The effect of being unemployed was opposite in a model without correction for selection effects (not shown). This result indicates that our population, which only includes people who accepted a job, is selective. Respondents who where unemployed one year before the interview are not representative of the whole population of unemployed people. Only those who where successful in finding a job have been included and so without correction our parameter estimates in the model are biased. When we correct for the fact that the population is selective, the unbiased parameters show more workplace mobility for the unemployed. This finding confirms the hypothesis that the need to accept a job at a greater distance is higher for the unemployed than for those who already have a job. For women there is no effect of former labour force status. Respondents who already had a job and commuted over a greater distance were more likely to accept another job located at some distance from where they lived.

The effect of job access confirms our main hypothesis: after controlling for individual characteristics determining spatial flexibility, people living in locations with poor access to suitable employment opportunities more often accept a job at a greater distance. With every extra 100,000 suitable jobs within reach, the odds for accepting a job over a long distance are decreased by a factor of 0.85 for men and 0.86 for women. So, for example, for a woman with access to 100,000 jobs within 30 minutes, the odds for accepting a job at a greater distance are estimated to be 1.60 times higher than for a woman with access to 400,000 jobs within 30 minutes. This finding indicates that accepting a job at a greater distance is partly driven by a shortage of suitable local employment opportunities.

\section{Discussion}

At national level workplace mobility is the mechanism that clears the labour market. Yet the existing literature shows that disequilibria among regional labour market persists owing to individual restrictions in accepting a job at a greater distance from the place of residence. To understand labour market adjustment adequately as a macro-level phenomenon, micro-level behaviour should be included in the conceptualization and in the empirical analysis.

In this contribution we have set out to extend the understanding of individual behavioural responses to a lack of suitable job opportunities on the local labour market. The starting point of the analyses is that workers facing such a lack have three options: staying put in their present job, or remaining unemployed; accepting a job within reasonable commuting distance from their residence, even if the job is beneath one's level of education; widening their search area and accepting a job at a greater distance, either by migrating or by accepting a long commute. Defining these behavioural outcomes as options is not to say that people can choose from them freely. Since the first and the second option are bound to lead to underemployment, the choice of these options is a matter of restrictions rather than preferences. 
Our analyses contribute to the existing literature on workplace mobility in four ways. The first of these is the use of a direct measure of workplace mobility: the distance at which people accept a job. In this way, workplace mobility is conceptualized more clearly than when commuting or job related migration is examined. The results show for instance that the conclusion from the migration literature, that married men and particularly fathers are less spatially mobile, is only partially true. Using the direct measure of workplace mobility it turns out that this group has higher general job mobility and are as likely as single men to accept a job at a greater distance. Obviously, for this group stretching their commuting tolerance is the alternative to migrating when accepting a new job.

Our second contribution is the distinction drawn between general mobility and workplace mobility in analysing labour market adjustment. The first result is that, in line with both the spatial mismatch hypotheses and the escalator region concept, ample availability of job opportunities increases the level of general job mobility. Our results also show that ignoring the category that has not found a job would lead to biased results in the analysis of workplace mobility. We found for instance that the fact that unemployed people less often accept a job at a greater distance is caused by the fact that they often lack the qualifications to secure a job, irrespective of distance. After controlling for this selectivity it appears that people with low chances of finding another job in general and the unemployed in particular actually accept a job at a greater distance more often.

The third contribution is the elucidation of gender differentials in labour market adjustment. It has repeatedly been claimed that women have fewer opportunities for career advancement owing to spatial restrictions that narrow the search area for another job. Our results show that women have an overall lower chance of finding another job. Being a spouse or a mother adds considerably to this effect. However, among the younger (under 45) and well-educated singles the chances for men and women are the same. After controlling for selectivity, we found that women do not have an overall lower chance of accepting a job at a greater distance and that highly educated women are more spatially mobile than men. Gender differentials do show up in the impact of the presence of a partner and children. For men, this presence does not limit their spatial flexibility; for women, it does. The conclusion is therefore that spatial inflexibility might contribute to the underemployment of women spouses and mothers, but not of women in general.

The fourth contribution is the incorporation of the job access of the residential location as a spatial context variable. With the use of FLOWMAP, a network-oriented Geographic Information System extension (see De Jong and Floor, 1993), we calculated the number of jobs, per job level, which could be reached from residential locations within 30 minutes. The results show that job access has a positive effect on general job mobility. The results also confirm our main hypothesis that people living in locations with poor access to suitable employment opportunities more often accept a job at a greater distance. Apparently, for many people, accepting a job at a greater distance is a precondition for taking a step up the career ladder. Our results show that the spatial context is important in explaining labour market adjustment. This idea is strengthened by the fact that the sector of the job also has a significant effect on workplace mobility. Sectors differ in the spatial distribution of jobs. Therefore, workers with sector specific human capital in a sector concentrated in only a few locations have to be more spatially flexible when accepting another job. The fact that the sector effect is less pronounced for women might indicate that they occupy less specialized jobs and can transfer their human capital between sectors more easily.

The inclusion of these macro-level variables may not however be optimal. Other variables, for example the number of suitable vacancies that can be reached, might measure the local opportunity set of job opportunities in a better way. Data on vacancies might also 
offer better opportunities for operationalizing suitability; in our data, the level of the jobs within reach is the only measure for suitability. More tailored measures of job access modelling might strengthen the analyses of the role of access to job opportunities in labour market adjustment. Unfortunately, data on vacancies is hard to obtain, seldom available, and of questionable reliability. Statistically, the standard errors of the job access variable might be underestimated, since job access has been measured at the level of postcodes rather than the individual. However, since the magnitude of the parameter is 4-5 times the standard error in our analysis, we are confident that a multi-level analysis would also have generated a significant effect of job access.

We therefore conclude with confidence that our findings show the importance of the residential location in avoiding costly workplace mobility. Workplace mobility serves as a mechanism to overcome poor local access to suitable jobs. This statement implies that for people who want to avoid mobility costs in terms of commuting and migration, those locations with the highest locational quality in terms of job access are the most favourable. These locations can be found at the edge of the larger cities, in between the major concentrations of employment. This is especially important for working women partners and mothers, since they are more spatially constrained than men and are therefore more dependent on local job opportunities. These locations will also be superior for the unemployed, some of which may remain outside employment due to their spatial inflexibility.

Acknowledgements. Maarten van Ham's research was supported by the Netherlands Organization for Scientific Research (grant nr.42513002). Clara Mulder's research was made possible by a fellowship from the Royal Netherlands Academy of Arts and Sciences.

\section{Notes}

1. The LISA datasets were obtained from the National Institute of Public Health and the Environment (RIVM, Bilthoven, The Netherlands) for the Ruimtescanner project.

\section{References}

Baccaïni B, 1997, "Commuting and residential strategies in the Ile-de-France: individual behaviour and spatial constraints" Environment and Planning A 29 1801-1829

Ballard K P, Clark G L, 1981, "The short run dynamics of interstate migration: a space-time economic adjustment model of in-migration to fast-growing states" Regional Studies 15 213-228

Bartel A P, 1979, "The migration decision: What role does job mobility play?" The American Economic Review 69 775-786

Bartel A P, Lichtenberg F R, 1987, "The comparative advantage of educated workers in implementing new technologies" Review of Economics and Statistics 69 1-11

Becker G S, 1962, "Human capital: a theoretical and empirical analysis" Journal of Political Economy 70 9-46

Becker G S, 1975 The economic approach to human behaviour (The University of Chicago Press , Chicago, IL)

Becker G S, 1991 A treatise on the family; enlarged edition (Harvard University Press, Cambridge, Massachussets)

Blumen O, 1994, "Gender differences in the journey to work" Urban Geography 15 223-245

Booth A L, Francesconi M, Garcia-Serrano C, 1999, "Job tenure and job mobility in Britain" Industrial and Labor Relations Review 53 43-70 
Börsch-Supan A, 1990, "Education and its double-edged impact on mobility" Economics of Education review 9 39-53

CBS (Statistics Netherlands), 1993 Standaard Beroepenclassificatie 1992 (Standard Job Classification 1992) (Sdu, The Hague)

Cohen J, Cohen P, 1975 Applied multiple regression/correlation analysis for the behavioural science (Wiley \& Sons, New York)

Crampton G R, 1997, "Labour-market search and urban residential structure" Environment and Planning A 29 989-1002

DaVanzo J, 1978, "Does unemployment affect migration? Evidence from micro data" The Review of Economics and Statistics 60 504-514

DaVanzo J, 1981, "Microeconomic approaches to studying migration decisions", in Migration decision making. Multidisciplinary approaches to microlevel studies in developed and developing countries Eds G F de Jong, R W Gardner (Pergamon Press, New York) pp $90-129$

De Jong T, Floor H, 1993, "Flowmap: een programma voor het weergeven en analyseren van interactiegegevens" (Flowmap: a software package for displaying and analysing interaction data) Planning, methodiek en toepassing 44 16-31

Duncan P R, Perrucci C C, 1976, "Dual career families and migration" American Sociological Review 41 252-261

Fernandez J P, 1981 Racism and sexism in corporate life: changing values in American business (Lexington Books, Lexington, Mass.)

Fielding A J, 1992, "Migration and social mobility: South East England as an escalator region" Regional Studies 26 1-15

Fielding A J, Halford S, 1993, "Geographies of opportunity: a regional analysis of genderspecific social and spatial mobilities in England and Wales, 1971-81" Environment and Planning A 25 1421-1440

Fisher M M, Nijkamp P, 1987, "Spatial labour market analysis: relevance and scope", in Regional Labour Markets Eds M M Fisher, P Nijkamp (North Holland, Amsterdam) pp 1 - 36

Gilbert M R, 1998, "Race, space, and Power: the survival strategies of working poor women" Annals of the Association of American Geographers 88 595-621

Giuliano G, 1998, "Information technology, work patterns and intra-metropolitan location: a case study" Urban Studies 35 1077-1095

Gordon P, Kumar A, Richardson H W, 1989, "Gender differences in metropolitan travel behaviour" Regional Studies 23 499-510

Hägerstrand T, 1970, "What about people in regional science?" Papers of the Regional Science Association 24 7-21

Hanson S, Pratt G, 1990, "Geographic perspectives on the occupational segregation of woman" National Geographic Research 6 376-399

Hanson S, Pratt G, 1991, "Job search and the occupational segregation of women" Annals of the Association of American Geographers 81 229-253

Hanson S, Pratt G, 1995 Gender, work, and space (Routledge, London and New York)

Hanson S, Kominiak T, Carlin S, 1997, "Assessing the impact of location on women's labor market outcomes: a methodological explanation" Geographical Analysis 29 281-297

Heckman J, 1979, "Sample selection bias as a specification error" Econometrica 47 153-161

Johnston-Anumonwo I, 1992, "The influence of household type on gender differences in work trip distance" Professional Geographer 44 161-169

Jarvis H, 1999, "Identifying the relative mobility prospects of a variety of household employment structures, 1981 - 1991" Environment and Planning A 31 1031-1046 
Kain J, 1968, "Housing segregation, negro employment, and metropolitan decentralization" Quarterly Journal of Economics 82 175-197

Keith K, McWilliams A, 1999, "The returns to mobility and job search by gender" Industrial and Labor Relations Review 52 460-477

Lichter D T, 1980, "Household migration and the market position of married women" Social Science Research 9 83-97

Lichter D T, 1982, "The migration of dual worker families: does the wife's job matter?" Social Science Quarterly 63 48-57

Lichter D T, 1983, "Socioeconomic returns to migration among married women" Social Forces 62 487-503

Madden J F, 1981, "Why women work closer to home" Urban Studies 18 181-194

March, J G, Simon H A, 1958 Organizations (Wiley, New York)

Markham W T, Pleck J H, 1986, "Sex and willingness to move for occupational advancement: some national sample results" Social Science Quarterly 27 121-143

Markham W T, Macken P O, Bonjean C M, Corder J, 1983, "A note on sex, geographic mobility, and career advancement" Social Forces 61 1138-1146

McLafferty S, Preston V, 1997, "Gender, race, and the determinants of commuting: New York in 1990" Urban Geography 18 192-212

Mincer J, 1962, "On the job training: costs, returns, and some implications" Journal of Political Economy 70 50-79

Mincer J, 1978, "Family migration decisions" Journal of Political Economy 86 749-773

Mulder C H, 1993 Migration dynamics: a life course approach (Thesis Publishers, Amsterdam)

Mulder C H, Hooimeijer P, 1999, "Residential relocations in the life course" in Population Issues. An interdisciplinary focus Eds L J G Van Wissen, P A Dykstra (Kluwer Academic/Plenum Publishers, New York) pp 159 - 186

Ong P, Blumenberg E, 1998, "Job access, commute, and travel burden among welfare recipients" Urban Studies 31 77-93

Phelps E S, 1970, "Introduction: The new microeconomics in employment and inflation theory", in Microeconomic foundations of employment and inflation theory Ed E S Phelps ES (Norton, New York) pp 1 - 26

Polachek S W, Horvath F W, 1977, "A life cycle approach to migration: analysis of the perspicacious peregrinator", in Research in labor economics: an annual compilation of research (volume 1) Ed R G Ehrenberg (JAI Press, Greenwich, Connecticut) pp 103 150

Pratt G, Hanson S, 1991, "Time, space, and the occupational segregation of women: a critique of human capital theory" Geoforum 22 149-157

Preston V, McLafferty S, 1999, "Spatial mismatch research in the 1990s: progress and potential" Papers in Regional Science 78 387-402

Ritchey P N, 1976, "Explanations of migration" Annual Review of Sociology 2 363-404

Rouwendal J, 1999, "Spatial job search and commuting distances" Regional Science and Urban Economics 29 491-517

Shaklee H, 1989, "Geographic mobility and the two-earner couple: expected costs of a family move" Journal of Applied Social Psychology 19 728-743

Simpson W, 1992 Urban structure and the labour market: worker mobility, commuting and underemployment in cities (Clarendon Press, Oxford)

Sjaastad L A, 1962, "The costs and returns of human migration" Journal of Political Economy 70 80-93 
Topel R H, Ward M P, 1992, "Job mobility and the careers of young men" Quarterly Journal of Economics 107 439-479

Turner T, Niemeier D A, 1997, "Travel to work and household responsibility: new evidence" Transportation 24 397-419

Van Ham M, Hooimeijer P, Mulder C H, 2001, "Urban form and job access: disparate realities in the Randstad" forthcoming in Tijdschrift voor Economische en Sociale Geografie 92

Van Ham M, Mulder C H, Hooimeijer P, forthcoming, "Job search, underemployment and the discouraged worker effect" forthcoming in Urban Studies

Van Ommeren J, 1996 Commuting and relocation of jobs and residences: a search perspective (Vrije Universiteit, Amsterdam)

Van Ommeren J, Rietveld P, Nijkamp P, 1999, "Impacts of employed spouses on job-moving behaviour" International Regional Science Review 22 54-68

Wachs M, Taylor B D, 1993, "The changing commute: a case study of the jobs-housing relationship over time" Urban Studies 30 1711-1730

Wagner M, 1989 Räumliche Mobilität im Lebensverlauf. Eine empirische Untersuchung sozialer Bedingungen der Migration (Spatial mobility in the life course. An empirical investigation of the social determinants of migration) (Enke, Stuttgart) 
Figure 1. Job access within 30 minutes (number of jobs)

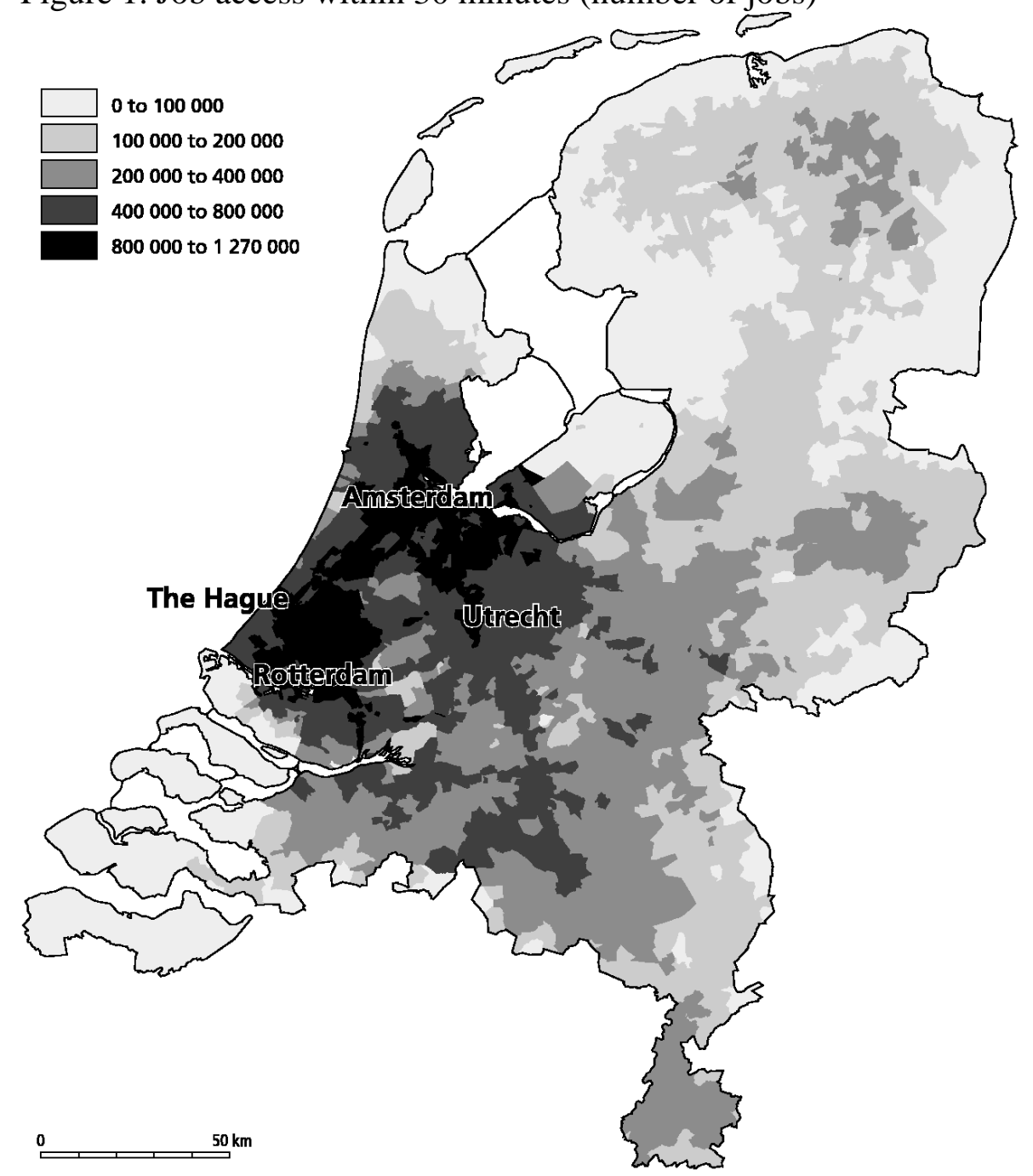

Source: LISA 1991 and 1994, based on own calculations 
Table 1. List of hypotheses

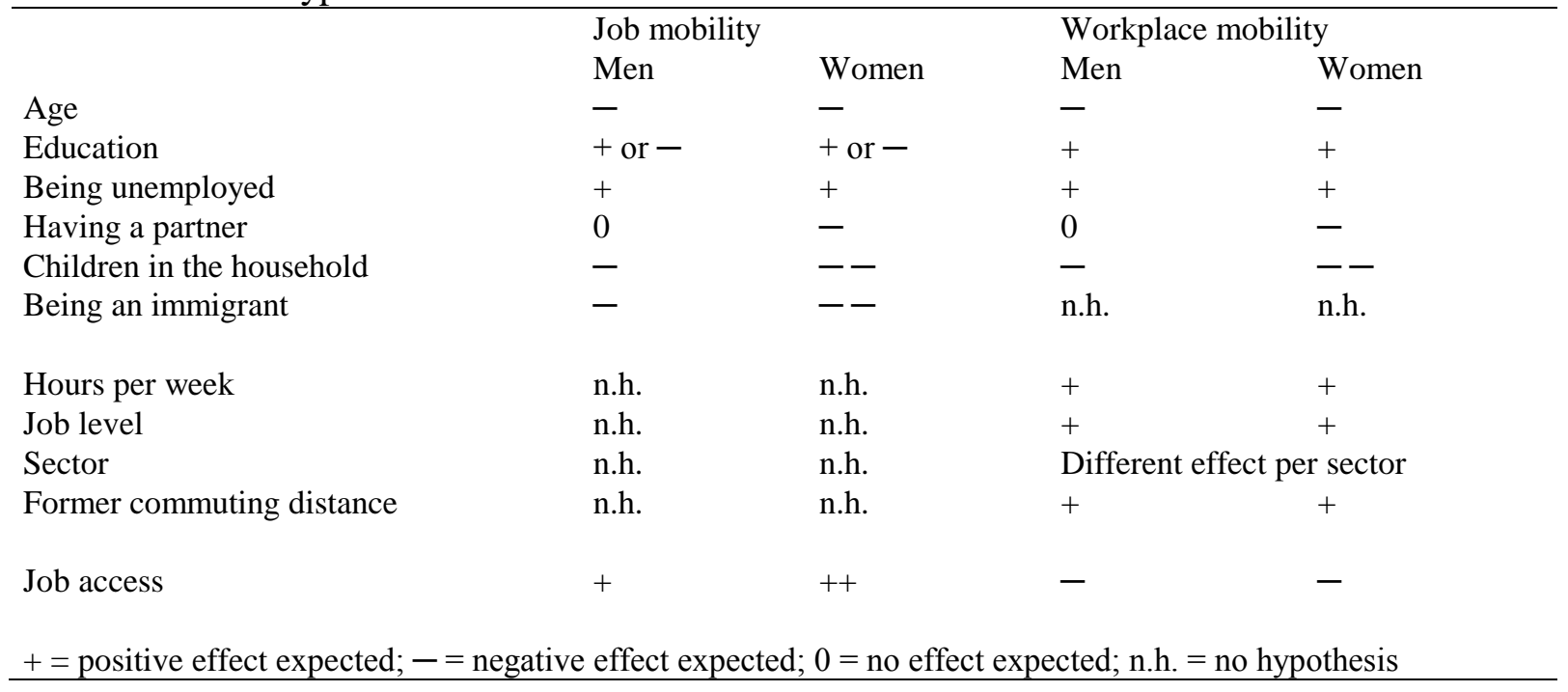


Table 2. Logistic regression of job mobility by gender

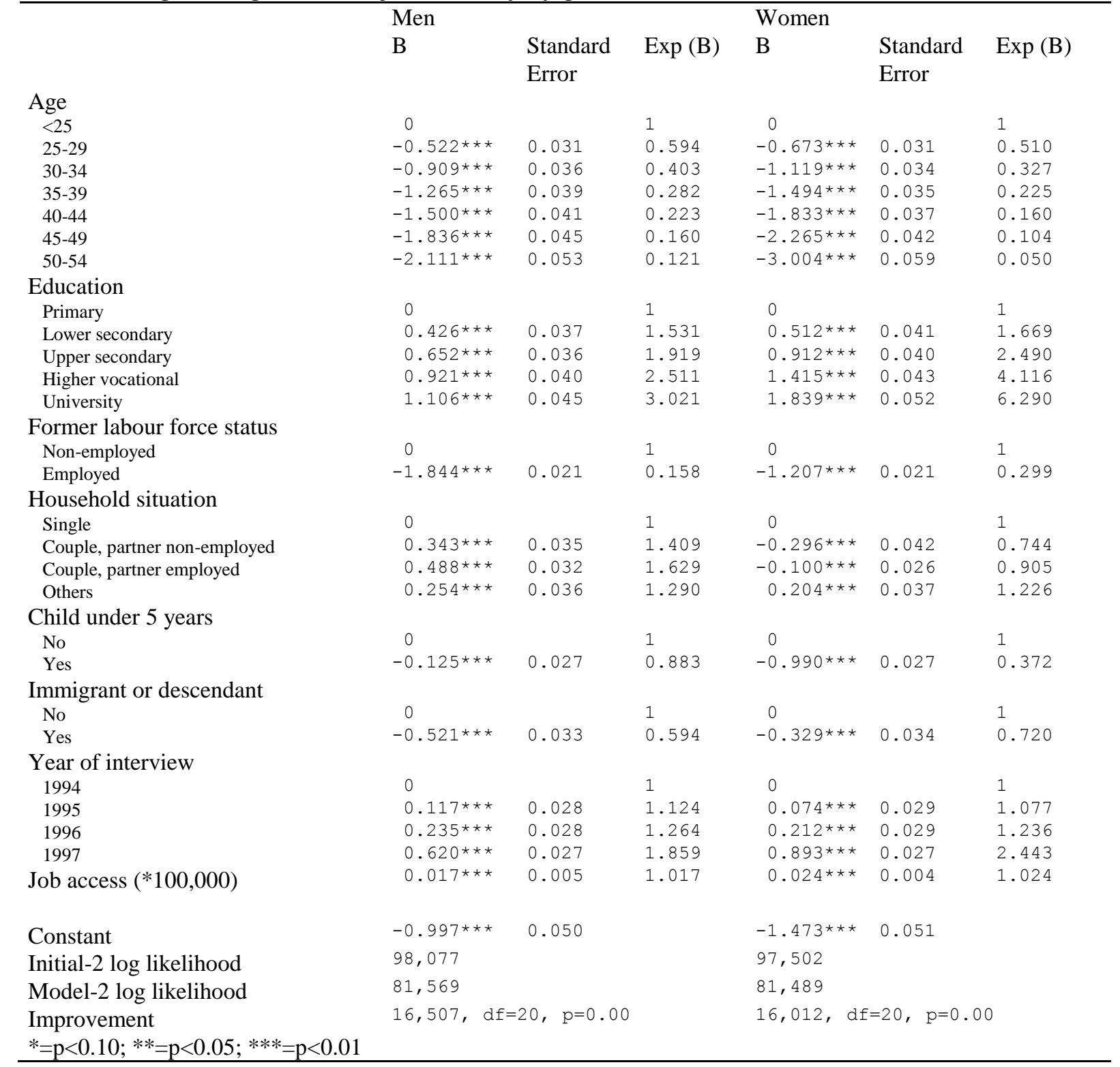


Table 3. Logistic regression of workplace mobility by gender

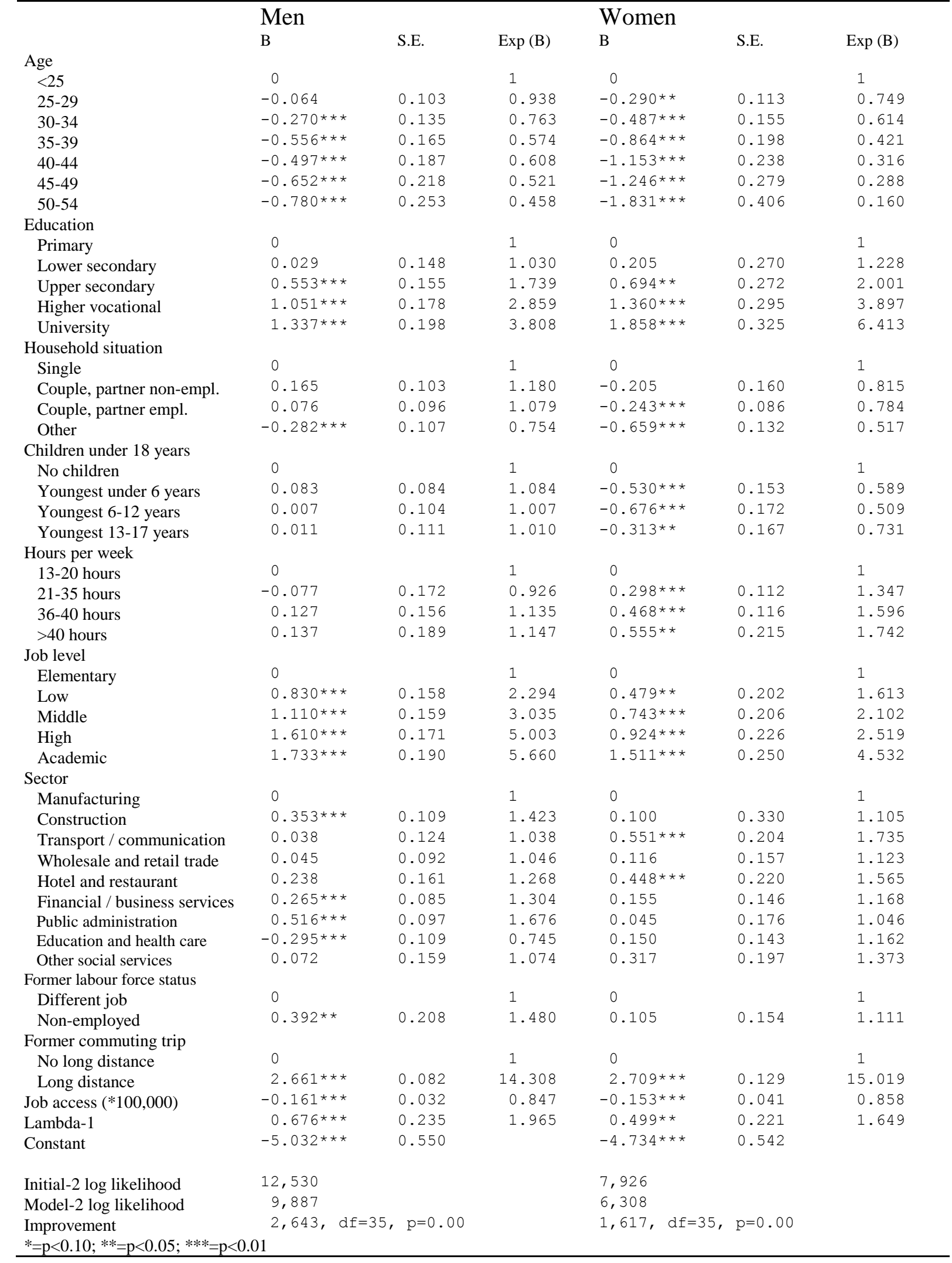

